\title{
Strengthening the links between nutrition and health outcomes and agricultural research
}

\author{
Anna Herforth ${ }^{1} \cdot$ Preetmoninder Lidder $^{2} \cdot$ Margaret Gill $^{3}$ \\ Published online: 25 April 2015 \\ (C) The Author(s) 2015. This article is published with open access at Springerlink.com
}

Keywords Agriculture-nutrition $\cdot$ Research $\cdot$ Indicators · Diet quality $\cdot$ Food safety

\section{Rationale and approach to the topic}

One of the well-recognised challenges in inter-disciplinary research is the difference between disciplines in how important goals are understood and, in turn, acted upon. In seeking to strengthen the links between agricultural research and nutrition and health outcomes, a key factor may be creating a shared understanding of what outcomes are intended to be improved, and how (Hinricks 2008; Levitt et al. 2009). Historically, nutritionists have often focused on consumption or indicators of nutritional status, and agriculturalists frequently assume that increased food production and income will lead to improved nutrition (World Bank 2014). It has thus proven challenging to align discourse and expectations among stakeholders for nutrition impact of agricultural investments and interventions.

The Independent Science and Partnership Council (ISPC) of the CGIAR (a global partnership of international agricultural research centers) organised a Science Forum in 2013 to "explore recent evidence across a range of disciplines and to

Anna Herforth

anna@annaherforth.net

1 Independent Consultant, New York, USA

2 CGIAR Independent Science and Partnership Council Secretariat, FAO, Rome, Italy

3 Institute of Biological \& Environmental Sciences, 23 St Machar Drive, Aberdeen AB24 3UU, UK identify priority research needs and new scientific approaches, including facilitating new and stronger partnerships, through which the agricultural community can add most value to the delivery of nutrition and health outcomes." The Forum was attended by participants with a wide range of interests, including scientists, practitioners, policymakers and staff from funding agencies. Discussion at the Forum led to agreement that agricultural research could have more impact on nutrition and health outcomes by prioritizing research questions about nutritious food access (e.g. cost reduction), diet quality, and food safety, and generally that impact should be measured by appropriate and more proximal indicators than stunting (ISPC 2014). The aim of this series of papers is to highlight some of the changes in the contexts in which agricultural research results will be implemented, and to illustrate how agricultural research can contribute to an essential determinant of nutrition: the provision of safe, nutritious, affordable foods.

Although food security was identified as "sufficient, safe, nutritious food to meet dietary needs and food preferences for a healthy and active life," nearly 20 years ago at the World Food Summit in 1996, this focus is still functionally a shift from the traditional priorities for agricultural research, which have primarily been the provision of staple grains and income. In the decades following the second World War (the 195070 s), the world was not producing sufficient calories to feed its growing population, and malnutrition rates - estimated from caloric availability at the time - were a cause for concern. The priority of increasing food production became a strong focus of agricultural research, marked by the Green Revolution, and the genesis of the CGIAR in 1971. Agricultural research was indeed successful in the latter quarter of the 20th century in rapidly and significantly increasing production of staple grains (mainly rice, wheat, and maize) and the supply of total food calories. As a consequence, with the quantity of food being 
produced no longer being perceived as limiting, growth in investment in agricultural research and development declined until the next significant food price spike in 2007-08 (Beintema and Elliott 2009; World Bank 2014). Together with concerns about the future impact of climate change on food production, the food crisis led to a number of significant assessments of the future of food systems (e.g. OECD 2008; IAASTD 2009) which explored priority areas for action, to ensure the world could feed its predicted population in 2050. An analysis of a range of assessments of environmental change and food systems by Wood et al. (2010), however, pointed out that the approaches taken were still predominantly focused on the production element of the global food system. Wood et al. recommended broader cross-sectoral engagement (including agriculture and nutrition, but also economics and social sciences, health, education) in such assessments from the start, to fully represent all the major contributors to food systems. Meanwhile political commitment to addressing malnutrition has grown since 2008, and many countries and donors are now seeking to determine how agriculture can best contribute to nutrition outcomes, having pledged USD 19 billion for "nutrition-sensitive" development in 2013 (Government of UK 2013). The time is ripe, therefore, for a more intense dialogue between the nutrition and agricultural research communities.

In 2011, the International Food Policy Research Institute (IFPRI) organised a conference in Delhi, India, to "inform, influence and catalyse key actors to better use agricultural investments to sustainably reduce malnutrition and improve health for the world's most vulnerable people." This conference identified a paucity of evidence based on intervention studies that link agriculture and nutrition (IFPRI 2011). Subsequently, donors funded a number of programmes and projects at this interface, to develop an evidence base on what does work, with the intention of improving research design. A review by Ruel and Alderman (2013) continued to highlight the contribution of weak study design to lack of evidence of impact, together with the confounding effects of other factors such as access to water, sanitation, and hygiene. Their paper suggests that "future work should include testing of programmes with stronger designs, nutrition goals, and interventions; use of rigorous programme-theory based impact and impact pathway assessments; and assessment of cost and cost-effectiveness."

The Science Forum organised by the ISPC (co-hosted by the Federal Ministry for Economic Cooperation and Development - BMZ, Germany) in 2013 took the title: Nutrition and Health Outcomes: Targets for agricultural research. Forum discussions identified the need to conduct research which focuses on better understanding of some of the pathways between agriculture and nutrition as well as how to measure or evaluate progress along them. Another area in need of further exploration was how research could help to ensure poor consumers had access to diverse, nutritious foods. ${ }^{1}$ These two broad topics were explored in more detail at a joint Agriculture for Nutrition and Health (A4NH)/ISPC follow-up workshop held at IFPRI exactly one year after the Science Forum. Some of the key findings from that workshop are elaborated on in the following section, showing the evolution of thinking over the last 12 months, as an introduction to the papers for this linked series.

\section{Key findings of the workshop}

Context and indicators that link agricultural research to nutrition impact Many of the presentations touched on the dynamism of changes in the context in which research outputs by both the agriculture and nutrition research communities will be used. In particular, there are changes in demand - diets can differ markedly between countries, and diets are not static over time, especially as incomes rise from a low base. Markets are changing - regional markets are important for many poor consumers. The private sector is also changing, with increasing attention to and investment in the health value of food. When designing research questions on impact, it is important to identify who will use the results and how they will be used. Similarly, it is important to recognize enabling or obstructing factors in the local context, and how nutrition improvements will be measured to show the results of the intervention. As research investors push for evidence of impact, more accountability for development outcomes is being expected from the CGIAR. It is, however, challenging to attribute positive impact specifically to agriculture in multi-sectoral interventions.

So what should agriculture be held accountable for in terms of improving nutrition? There was unanimous agreement during the discussions that there is a need to focus relatively more on diet quality, which sits at the heart of food systems. Agricultural interventions can improve information about their impact by measuring food consumption and dietary quality outcomes, as well as their effect on food environments. Dietary diversity is increasingly recognized as a useful indicator for capturing some aspects of diet quality, as it correlates with adequacy of nutrient intake (Arimond et al. 2010). Bearing in mind the rising problems of obesity and diet-related noncommunicable diseases (NCDs), workshop participants considered that agriculture-nutrition research would benefit from developing indicators that take into account additional indicators of dietary quality and food environments, such as food groups that should be consumed in moderation. A rule of thumb should be that interventions do not cause adverse

\footnotetext{
${ }^{1}$ The briefs from the 2013 Science Forum as well as the follow-up workshop are available at http://ispc.cgiar.org/mobilize.
} 
effects (e.g., reduction in diet quality, disease risk or food safety issues, or worsening of women's agency and time and resource allocation). Therefore in agricultural interventions to improve nutrition it is important to track indicators for outcomes all along the impact pathway, not just those related to diet and nutrition outcomes.

\section{Access to nutritious and safe diets at an affordable}

price The workshop also considered priority research questions associated with helping to ensure access to adequate, diverse, nutritious, sustainably-produced foods. Both supply and demand side constraints exist for foods that tend to be most nutrient-rich, including legumes, fruits and vegetables, and animalsource foods. Continued investment in making staples more nutrient-rich should not be undermined, but additional emphasis in the research agenda on non-staple, nutrient-rich foods is crucial (e.g., developing the seed system for nutrient-rich crops, ensuring that nutrient-rich foods can be marketable, better infrastructure to serve multiple crops and reduce post-harvest loss, more investment in processing and increasing convenience, etc.). One area of increasing interest was how to facilitate smallholder farmer participation in markets. Addressing challenges in the marketplace will help diversify diets (e.g., by reducing constraints to produce, store, process, transport and market nutritious foods for urban and rural populations). For smallholder farmers to effectively supply domestic markets with diverse nutritious foods, they must produce products for which there is demand, capability to be bulked, with reduced perishability or increased storage capacity, have high value for land size, or are capable of being farmed with other crops. A key area for action relates to efforts in managing food safety in informal markets in ways that remain pro-poor. Evidence from some low and lowermiddle income countries shows that wet markets are often no worse than supermarkets at meeting food safety standards, and gradual "formalization" of wet markets can improve safety and decrease poverty (Roesel and Grace 2015).

Value chains offer tremendous opportunities for improving nutrition by identifying leverage points through which dietary diversity can be enhanced; it is helpful to broaden the definition from single-commodity value chains to multiple-product value chains (i.e., a food system or value web). These opportunities include: identifying bottlenecks where unnecessary transaction costs exist; decreasing costs and/or increasing the value of the commodity (through processing, for example); understanding production versus consumption dynamics; creating demand by understanding and influencing consumer choice; and identifying policy and regulation actions and solutions. At the same time, there are critical risks for improved nutrition through value chain development that need to be taken into account. These include trade-offs between income and nutrition; risk of ignoring short value chains that do/can supply food to target populations (e.g., advantages for women's time) in favor of long value chains (international, high income urban markets); concerns about exclusivity and whether value chains and food systems can actually reach the most vulnerable; unintended consequences of commercialization; and risks to food safety associated with intensification.

\section{The papers in this special section}

Some of the presentations at the workshop were based on papers which are published here.

This special section has three groups of papers. The first three set the stage by laying out the context of the enabling socio-political environment, and desired outcomes of the food system: improving multiple aspects of nutrition simultaneously, and sustainably within environmental boundaries. Gillespie et al. present a qualitative study about how stakeholders in East Africa and South Asia believe agriculture can influence nutrition, what policy opportunities and barriers exist, and what stakeholders see as the needs for research and capacity to improve linkages. The global community of nutrition stakeholders has set targets in the form of six World Health Assembly targets for nutrition. Webb et al. show how these could be synthesized into a multi-dimensional index of nutrition. The index highlights that obesity and undernutrition coexist, and many countries that have made significant gains in reducing undernutrition perform less well in terms of preventing obesity - including those that have raised agricultural GDP (Webb and Block 2012). Such an index could be useful to understand where and how agriculture research and development supports the reduction of all forms of malnutrition. Along with the multiple indicators of malnutrition summarised by Webb et al., increases in stocks of environmental assets need to be a target of agricultural research and development (Sayer and Cassman 2013); specifically, how nutritious diets can be produced with the best environmental outcomes. Gill et al. raise the question of how the nutrition transition affects environmental indicators. They use trends in Brazil, China and India to explore the impact of changes in supply per capita (as distinct from population growth) on environmental indicators including greenhouse gas emissions, nutrient cycles, water use, and land use. They highlight the need to measure environmental impacts beyond those of greenhouse gas emissions.

The second set of papers deals with increasing access to nutritious, safe food through markets, as well as non-market channels. Much of the evidence base that has been discussed on agriculture-nutrition linkages focuses on production and consumption within the farming household. This collection of papers, following on from the discussions at the Science Forum exploring the importance of markets, addresses questions of how market access, integration, income, and the food availability in markets might affect nutrition. Although income is often discussed as a pathway between agriculture and nutrition, Herforth and Ahmed show that the effect of income on diet is 
always modified by the "food environment" in markets, which they define as the availability, affordability, convenience, and desirability of various foods in the market. They suggest that the impact of agricultural policy and even programs could be designed and understood better if the food environment could be characterized, and their paper discusses metrics of the food environment. Darrouzet-Nardi and Masters show that farm households with better access to markets have lower rates of undernutrition among children. However, they find that proximity to markets also increases the risks for overweight among children and women, again pointing to questions around how the food market environment might better support reductions in undernutrition without rises in diet-related chronic disease. Powell et al. describe a different kind of food environment: the cultivated and wild sources of foods, which are significant for many people, particularly rural-dwellers. They review existing evidence that links wild and cultivated biodiversity with nutrition outcomes, which show apparent positive relationships, although large research gaps remain. Biofortification is a route through which the CGIAR has invested in increasing micronutrient intake in staples, as a complementary route to diversification of production and diets. Birol et al. implicitly consider the importance of the food environment in their paper, which compares different methods to measure consumer acceptance of biofortified foods for five crops across seven countries in Africa, Asia and Latin America. The authors highlight the need to understand the differences in acceptance of visible versus invisible traits and conclude that knowledge of which biofortified foods are acceptable to consumers is needed before scaling up production of specific (biofortified) crops. As markets grow, issues of food safety are increasingly recognised. Aflatoxins have been identified by the CGIAR as the most important human health concern associated with staple crops. Grace et al. use four case studies of different approaches to decreasing the risks of aflatoxin contamination to explore how agricultural research can contribute to enhanced food safety, whilst also improving accessibility for poor consumers and access to markets for smallholder farmers. They demonstrate how taking economic and epidemiological perspectives could help to connect nutrition and health outcomes.

The last two papers synthesize what this current research means for agricultural research and policy. Pingali argues that staple grains have been a preoccupation within agricultural research and investment, and that it is time to move away from "crop fundamentalism" that does not support agriculture to respond effectively to consumer demand for diversity. Pingali suggests that levelling the playing field through crop neutral support could open up markets for farmers while increasing availability of diverse, nutritious food in the market. The CGIAR centers were initially formed in the 1970s to improve yields of the major staple crops; an agenda that may need to be broadened for it to best improve access to adequate diverse, nutritious foods. In the final paper, McDermott et al. call for a "fundamental change" in how agricultural research is designed to contribute to nutrition outcomes, with a strong focus on what drives consumption from both demand and supplyside perspectives. They call for broader partnerships, reaching beyond commodity value chains to engage with participants across the broader food system including policymakers.

Overall the papers illustrate how global food systems are changing and suggest how agricultural research needs to change if it is to make a major contribution to nutrition and health outcomes.

Acknowledgments The papers in this special feature were inspired by a Science Forum co-hosted by the Federal Ministry for Economic Cooperation and Development (BMZ) Germany in September 2013. We would like to thank the Steering Committee for contributing valuable ideas. We are also grateful to the reviewers for insightful comments on the manuscripts.

Open Access This article is distributed under the terms of the Creative Commons Attribution License which permits any use, distribution, and reproduction in any medium, provided the original author(s) and the source are credited.

\section{References}

Arimond, M., Wiesmann, D., Becquey, E., Carriquiry, A., Daniels, M. C., Deitchler, M., et al. (2010). Simple food group diversity indicators predict micronutrient adequacy of women's diets in 5 diverse, resource-poor settings. The Journal of Nutrition, 140, 2059S-2069S.

Beintema, N., \& Elliott, H. (2009). Setting meaningful investment targets in agricultural research and development: challenges, opportunities and fiscal realities. In How to feed the World in 2050. Proceedings of a technical meeting of experts, Rome, Italy, 24-26 June 2009. ftp:// ftp.fao.org/docrep/fao/012/ak542e/ak542e00.pdf. Accessed on 01 December 2014.

Government of UK. (2013). Nutrition for Growth Commitments. https:// www.gov.uk/government/uploads/system/uploads/attachment_data/ file/207274/nutrition-for-growth-commitments.pdf. Accessed 01 December 2014.

Hinricks, C. C. (2008). Interdisciplinarity and boundary work: challenges and opportunities for agri-food studies. Agriculture and Human Values, 25, 209-213.

IAASTD (International Assessment of Agricultural Knowledge, Science, and Technology for Development). (2009). Agriculture at a Crossroads (Synthesis Report). Washington: Island Press.

IFPRI (International Food Policy Research Institute) (2011). Leveraging Agriculture for Improving Nutrition and Health: Highlights from an International Conference. Washington, DC. http://www.ifpri.org/sites/ default/files/publications/oc66.pdf. Accessed on 01 December 2014.

ISPC (Independent Science and Partnership Council) (2014). Nutrition and Health Outcomes: Targets for Agricultural Research. Brief No. 43. http://ispc.cgiar.org/sites/default/files/ISPC_MobilizeScience SF2013 Brief_0.pdf. Accessed on 01 December 2014.

Levitt, E. J., Pelletier, D. L., \& Pell, A. N. (2009). Revisiting the UNICEF malnutrition framework to foster agriculture and health sector collaboration to reduce malnutrition: a comparison of stakeholder priorities for action in Afghanistan. Food Policy, 34, 156-165.

OECD (Organization for Economic Cooperation and Development). (2008). OECD environmental outlook to 2030. Paris: OECD. ISBN 978-92-64-04048-9. 
Roesel, K., \& Grace, D. (Eds.). (2015). Food safety and informal markets: animal products in sub-Saharan Africa. New York: Routledge.

Ruel, M., \& Alderman, H. (2013). Nutrition-sensitive interventions and programmes: how can they help to accelerate progress in improving maternal and child nutrition? Lancet, 382, 536-551.

Sayer, J., \& Cassman, K. (2013). Agricultural innovation to protect the environment. Proceedings of the National Academy of Sciences of the United States of America, 110(21), 8345-8348.

Webb, P., \& Block, S. (2012). Support for agriculture during economic transformation: impacts on poverty and undernutrition. Proceedings of the National Academy of Sciences of the United States of America, 109(31), 12309-12314.

Wood, S., Ericksen, P., Stewart, B., Thornton, P., \& Anderson, M. (2010). Major international environmental and food assessments: questions asked and lessons learned. In J. Ingram, P. Erickson, \& D. Liverman (Eds.), Food security and global environmental change. London, Washington: Earthscan.

World Bank. (2014). Learning from world bank history: agriculture and food-based approaches to address malnutrition (Agricultural and environmental sciences discussion paper 10). Washington: World Bank. World Bank Report No. 88740-GLB.

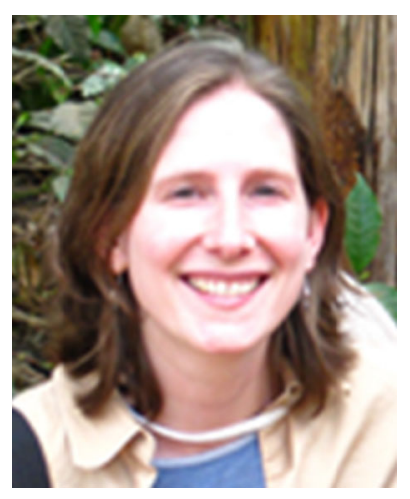

Anna Herforth Anna Herforth is a consultant specializing in the links between nutrition, agriculture and the environment. She consults for the World Bank, the UN Food and Agriculture Organization (FAO), and USAID's SPRI NG Project, among others. She has worked with universities, nonprofit organizations, and the CGIAR on food and nutrition in Africa, South Asia, and Latin America. She holds a Ph.D. from Cornell University in International Nutrition, an M.S. in Food Policy from Tufts Friedman School, and a B.S. in Plant Science from Cornell University. She is a founding member of the Agriculture-Nutrition Community of Practice (Ag2Nut).

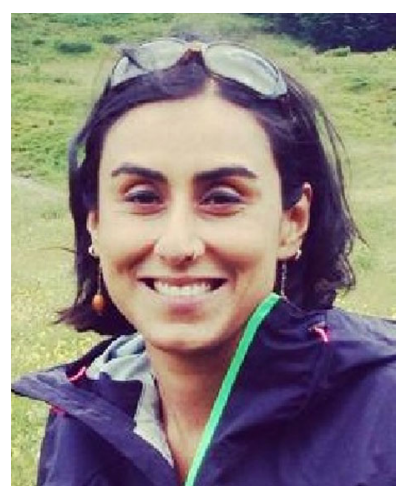

Preetmoninder Lidder Preetmoninder Lidder has been with the CGIAR Independent Science and Partnership Council Secretariat since September 2012. Prior to that, she worked with the UN FAO InterDepartmental Group on Biotechnology for 4 years. She trained as a molecular biologist with an M.S. in Plant Molecular Biology from the University of Delhi, and a Ph.D. in Cell and Molecular Biology from Michigan State University, followed by postdoctoral research on the retinal mosaic that supports color vision in Drosophila at New York University.

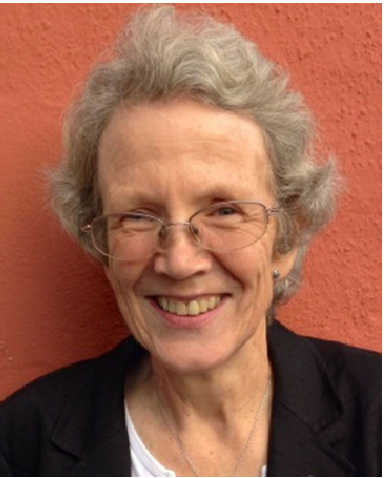

Margaret Gill Margaret Gill is the Chair of the Independent Science and Partnership Council of the CGIAR and also a Professor of Integrated Land Use at the University of Aberdeen. Previous posts have included Chief Scientific Adviser on Rural Affairs and the Environment in the Scottish Government, Chief Executive of the Macaulay Land Use Research Institute in Aberdeen and Chief Executive of Natural Resources International Ltd. Her research career was originally in ruminant nutrition, subsequently on the impacts of livestock systems on the environment before she moved into research management positions. 